\title{
Profile of Non-Communicable Disease Risk Factors Among Employees at a Saudi University
}

\author{
Tarek Tawfik Amin ${ }^{1 *}$, Ali Ibrahim Al Sultan ${ }^{2}$, Ola Abdelmoniem Mostafa ${ }^{1}$, Amr \\ Ahmed Darwish $^{3}$, Mohamed Rashad Al-Naboli ${ }^{3}$
}

\begin{abstract}
Background: There is paucity of studies defining the prevalence of non-communicable disease (NCD) risk factors in Saudi Arabia despite the surging epidemic of obesity, change in dietary habits and sedentary lifestyle. Objectives: This cross-sectional study aimed to assess the prevalence of NCDs risk factors among employees at King Faisal University in Al Hassa, Saudi Arabia and to determine the possible correlates for clustering of NCDs risk factors among them. Materials and Methods: All employees were invited to participate; the World Health Organization STEPwise approach was used for data collection which consisted of a personal interview to collect socio-demographic characteristics, NCD history, tobacco use, vegetables and fruit consumption, and physical activity (PA), followed by anthropometric measurements namely weight, height and waist circumference and blood pressure measurements, subjects were finally subjected to biochemical tests with determination of fasting plasma glucose, serum triglycerides, cholesterol and high density lipoproteins. Results: Of the surveyed employees $(n=691)$, daily current smokers accounted for $22.7 \% .94 .9 \%, 95.1 \%$ and $86 \%$ consumed $<5$ servings per day of vegetables, fruits and both fruits and vegetables respectively, $73 \%$ were physically inactive, $64 \%$ were overweight or obese, $22.1 \%$ had hypertension, and $21.5 \%$ were diabetics. Elevated cholesterol levels were found in $36.6 \%$, low high density lipoproteins in $\mathbf{3 6 . 8 \%}$, and elevated triglycerides in $36.1 \%$. Only $3 \%$ had no NCD risk factors, and $57.6 \%$ had $\geq 3$ factors. Multivariate logistic regression showed that gender (being male, adjusted odds ratio 'aOR'=1.51), aged $\geq 50$ years $(\mathrm{aOR}=3.06),<$ college education $(\mathrm{aOR}=1.75)$, current smokers $(\mathrm{aOR}=2.37)$, being obese $(\mathrm{aOR}=6.96)$ and having a low $\mathrm{PA}$ level $(\mathrm{aOR}=4.59)$ were the significant positive predictors for clustering of NCD risk factors. Conclusions: Over fifty percent of the studied university's employees had multiple ( $\geq 3$ ) NCD risk factors. Screening and health promotion initiatives should be launched at least targeting the modifiable factors to avert the excessive risk for cardiovascular disease, diabetes mellitus and several types of cancers.
\end{abstract}

Keywords: Non-communicable diseases - risk factors - STEPwise - university employees - Saudi Arabia.

Asian Pac J Cancer Prev, 15 (18), 7897-7907

\section{Introduction}

Of the 36 million deaths from non-communicable diseases (NCDs) worldwide in 2008 (W.H.O., 2012), 7.6 million $(\approx 20 \%)$ were due to cancer. The global cancer incidence is projected to increase from 13.3 to 21.4 million per year between 2010 and 2030 (Ferlay et al., 2010). By 2030, approximately half of all cancers globally will occur in low and middle income countries (W.H.O., 2012). The important known risk factors for NCDs are high blood pressure, high serum cholesterol, excess weight, inadequate vegetables and fruits intake, physical inactivity (PinA) and tobacco use. These factors are interrelated having multiplicative effect with evolvement of NCDs even in a person with modest elevation of several risk factors (Murray and Lopez, 1996). The shared environmental and behavioral risk factors for NCDs made an important contribution to the global cancer burden (Lim et al., 2010; Wild, 2012). The global impact of tobacco with cancer in multiple organs (Cogliano et al., 2011), the linked association between insufficient PA and breast, colorectal and endometrium cancers are well recognized (AICR, 2007). Also, reducing the consumption of sugar should help control obesity and overweight, which are risk factors for cancers of the esophagus, breast, colorectum, endometrium, kidney, and pancreas (AICR, 2007). NCDs especially cardiovascular, cancer, and type 2 diabetes mellitus are accounting for $>50 \%$ of all deaths and disability adjusted life years lost in the Eastern Mediterranean Region including the Gulf states (Musaiger and Al-Hazzaa, 2012).

Future projections of NCD prevalence rates might reach epidemic proportions, with serious consequences on mortality, productivity and health-care expenditure

${ }^{1}$ Public Health and Community Medicine, Faculty of Medicine, Cairo University, Cairo, Egypt, ${ }^{2}$ Internal Medicine, College of Medicine, Dammam University, ${ }^{3}$ Internal Medicine, College of Medicine, King Faisal University, Riyadh, Saudi Arabia *For correspondence:amin55@myway.com 
(Zaghloul et al., 2011). The burden of these diseases is particularly high in Arab countries including Saudi Arabia (Hazzaa et al., 2011). Saudi Arabia is witnessing a rapid economic advancement in the recent decades. This advancement is coupled with change in the socioeconomic structure and change in the population's lifestyle reflected in more sedantarism and adoption of westernized eating habits (Amin et al., 2014), with the emergence and abundance of NCDs risk factors in the form of physical inactivity and unhealthy dietary habits, most of NCDs including various types of cancers are showing disproportionate increase in Arab Gulf countries including Saudi Arabia (W.H.O., 2001). Prevention of many NCDs including cancers stemmed from the control of modifiable risk factors, therefore primary prevention of these risk factors through identification and appropriate management may help in delaying and halting the progression of many NCDs (Wild, 2012). There is paucity of studies that defined the prevalence of NCDs risk factors in Saudi Arabia despite the surging epidemic of obesity, changing in dietary habits, sedentarism especially among those more likely at risk by the virtue of age, occupational status like universities' employees. The objectives of this study were to identify the prevalence of NCDs risk factors among the employees at King Faisal University in Al Hassa and to determine the possible predictors for clustering of NCDs risk factors among them.

\section{Materials and Methods}

\section{Setting and design}

King Faisal University is located in Al-Hassa Governorate, Eastern Province of Saudi Arabia and $450 \mathrm{Km}$ from Riyadh. The University encompasses ten colleges with a total manpower accounted for 2393 (year 2012), 790 women and 1603 men at various occupational categories (staff, management, clerical) and technical services. The employed population, their families and students receiving primary care services through a medical center located within the campus.

\section{Subjects and methods}

A cross sectional descriptive study in which all university's employees were eligible. Over four weeks duration employees were invited through multiple channels including; announcements on University's website, personal approach, and banners posted in administrative premises including health center and colleges, with distribution of brochures explaining the objectives, procedures, inclusion and exclusion criteria, the locations and dates assigned for each college and administrative facilities within the university campus for the study also announced and circulated within the campus. Participants' agreement and fasting for 10-12 hours were the inclusion criteria, being pregnant and the presence of conditions hindered PA seven days prior the interview were the exclusion criteria.

\section{Data collection}

World Health Organization STEPS methodology (W.H.O. STEP wise approach for Surveillance of Chronic
Non-communicable Diseases Risk Factors, version 3) (http://www.who.int/chp/steps/instrument/en/index. html) was employed for data collection. The STEPS instrument covers three different levels or 'steps' of risk factor assessment: Step 1 (questionnaire), Step 2 (physical measurements) and Step 3 (biochemical measurements). This method provided a validated framework for the surveillance of NCDs risk factors (W.H.O., 2002). STEPS is composed of several tools to gather information regarding socio-economic and behavioral risk profile, anthropometry, blood pressure measurements and biochemical testing including fasting blood sugar and lipid profile. The available Arabic version of the STEP was used for data collection.

Data collection spanned from $1^{\text {st }}$ of March 2012 to May $30^{\text {th }} 2012$. Ten trained interns ( 5 males and 5 females) on data collection (training included conduction of personal interview, data collection about the socio-demographic and behavioral risk factors: tobacco use, PA and dietary habits, and the use of show cards (two were designed, one to assist participants in responding about the consumption of fruits-vegetables available and the second to illustrate different PA patterns along work-and leisure -related domains suitable to Saudi culture). Two technicians (one male and one female) were trained for anthropometric and blood pressure measurements using standardized protocol with frequent calibration of the instruments used. The data collection procedures included the following:

\section{Step I personal interview with STEP questionnaire}

Socio-demographic data: age, education, nature of work within the university, residence and marital status.

Disease history: hypertension, diabetes mellitus, cardiac event or other vascular diseases with detailed inquires regarding age at diagnosis, follow ups and medications.

Tobacco use: current smoking status, forms of tobacco usage, duration of smoking, age at initiation and frequency.

Vegetables and fruit consumption in terms of frequency of consumption/week and average servings/ day, with demonstration of serving size of different food items using a show card.

PA along different domains of work-commuting- andleisure related was obtained using the Global Physical Activity Questionnaire (GPAQ).

Step II Anthropometry and blood pressure measurements

Weight was measured using commercial scale "Seca, Germany" with an accuracy of $\pm 100 \mathrm{Kg}$. Subjects were weighed barefooted and with minimal clothes. Scales were re-calibrated after each measurement.

Height was measured using commercial stadiometer, subjects were barefooted, with shoulders relaxed, and arms hanging freely. Height was approximated to the nearest $0.5 \mathrm{~cm}$. Body mass index (BMI) was calculated "Body weight in $\mathrm{kg} /$ Height in square meters".

Waist circumference was measured in centimeters using a measuring tape passing midway between the iliac crest and the lower costal margin.

Blood pressure was measured using OmRon sphygmomanometers (HEM-907XL) after fulfilling 
American Heart Association blood pressure measurement protocol (Pickering et al., 2004). Both systolic and diastolic pressures were measured at two occasions and the averages were recorded. Participants reporting current use of anti-hypertensive drugs were considered hypertensive regardless their blood pressure readings.

\section{STEP III Biochemical tests}

Finally all subjects were submitted to biochemical tests, blood samples were taken after sitting for at least 15 minutes and from the counter arm used for blood pressure measurement by two laboratory technicians (one male and one female). Venous blood samples were taken in the morning after twelve hours of fasting for determination of fasting plasma glucose (FBG) using glucose peroxidase method, also, serum triglycerides and cholesterol were measured using standard enzymatic procedures and high density lipoproteins were assessed by direct assay method Subjects were considered having impaired glucose level if FBG was $110-125 \mathrm{mg} / \mathrm{dl}$. Subjects with FBG $\geq 126 \mathrm{mg}$ / $\mathrm{dl}$ and those using medication to control diabetes were considered diabetics. For cholesterol level; borderline high if it was $=\geq 190 \mathrm{mg} / \mathrm{dl}$, high $(\geq 240 \mathrm{mg} / \mathrm{dl})$, triglycerides $\geq 150$ was considered borderline high, and high if it was $\geq 180 \mathrm{mg} / \mathrm{dl}$, and low high density lipoproteins level was considered if it was $<40 \mathrm{mg} / \mathrm{dl}$ in men and $<50 \mathrm{mg} / \mathrm{dl}$ in women (W.H.O. STEPwise approach). All biochemical tests were carried out at the University's Health Center.

\section{Data analysis}

Out of the total university's employees invited, 792 responded and agreed to participate $(33.1 \%$ response rate), 269 women (34.1\% response rate) and 523 men (32.3\% response rate). Forms with missing of $\geq 2$ items $(n=36)$, refused anthropometric assessment $(n=21)$ or declined blood sampling $(n=44)$ were excluded from the final analysis, 691 were the total eligible forms for final analysis. Data entry and analysis were carried out using SPSS 13.0 (SPSS Inc. Chicago, U.S.A.) and Epi-Info version 6.04 (Centers for Disease Control and Prevention, Atlanta GA., U.S.A) and analysis was performed according to STEP protocol. Categorical data were expressed in frequency and proportions, employing Chi square and trend analysis as appropriate. Continuous data were expressed using median, interquartile range (IQR), mean and standard deviations, t-test, Mann Whitney and Kruskal Wallis tests were used for comparison when indicated. PA was classified according to the GPAQ protocol into high, moderate and low PA categories (W. H.O, STEPS Instrument, version 3.0). The total metabolic equivalents (METs) of PA after applying tests of normality, namely Kolmogorov-Smirnov test revealed a statistic of $.431(\mathrm{p}=0.001)$. The previous figure rejected data normality, and hence we employed $95 \%$ confidence intervals (CI) for the median (50th percentiles) using method proposed by Bonett and Price (Bonett and Price, 2002) and IQR, to report PA in METs-minutes. Possible determinants for clustering of NCDs risk factors were assessed through generating an adjusted multivariate logistic regression model using the number of NCDs risk factors (dependent dichotomy of $<3 v s \geq 3$ ), namely low
PA of <600 METS/minute/week, current daily smoking, obesity with BMI of $>29.9$, consumption of fruits and vegetables $<5$ servings/day, hypertension $>140 / 90 \mathrm{mmHg}$, FBG $>126 \mathrm{mg} / \mathrm{dl}$, and the presence of dyslipidemia [cholesterol $\geq 240 \mathrm{mg} / \mathrm{dl}$, triglycerides of $\geq 180 \mathrm{mg} / \mathrm{dl}$ and/ or low high density lipoproteins] with socio-demographic and other independent variables significant at univaraite analysis and expressed in the form of Odds ratio with $95 \%$ confidence intervals. $p$ value of $<0.005$ was considered significant.

\section{Ethical considerations}

Permissions were obtained after approval of the study protocol and data collection forms. Participants signed an informed consent form after detailed orientation about the objectives, procedures and possible outcomes of the study. Two forms were designed, one for reporting the biochemical tests' results, and one for referral to the University's medical center in case of abnormal biochemical findings and/or behavioral risk factors for medical consultation and counseling.

\section{Results}

\section{Basic characteristics}

Table 1 demonstrates the socio-demographic characteristics and chronic diseases history among participants distributed by gender. A total of 691 participants, their age ranged from 24 to 63 years. Age category 30 to $<50$ years constituted $62.3 \%$ of participants and women constituted less than a third (28.7\%), and were relatively younger. Saudis constituted $76.8 \%$, Arab non-Saudis $18.6 \%$ (Egyptians, Sudanese, Tunisians, Syrians, Algerians, and Jordanians) and $4.6 \%$ were non Arabs; namely Indians, Pakistanis, and Bangladeshi nationals. Faculty constituted $36.6 \%$; Saudis $32.8 \%$ and Arab non-Saudis and non-Arabs accounted for $67.2 \%$. Hypertension was diagnosed in $13.5 \%$ (15.0\% and 9.6\% of hypertensive men and women respectively) reported non-compliance to medications. Nine percent were diagnosed as having diabetes mellitus type $2,11.4 \%$ mentioned non-compliance to treatment, and $3.0 \%$ had concurrent diabetes and hypertension, and $1.9 \%$ with history of coronary heart disease. Saudis and Egyptians were proportionately more affected with NCDs compared to other nationalities as they accounted for $76.8 \%$ of those diagnosed cases. Those occupying administrative jobs were more likely to have NCDs as they constituted $54.0 \%$ of the diagnosed diabetics, $50.0 \%$ of hypertensive, and $70.0 \%$ with coronary heart disease while faculties constituted $20.0 \%$ of diabetics, $32 \%$ of hypertensive, and $30.0 \%$ of coronary heart disease.

\section{Smoking and alcohol intake}

None of the participants stated alcohol consumption and none of the women included reported tobacco smoking in any form. Of the included men, $36.1 \%$ reported 'ever tried cigarette smoking. Occasional smoking (during social gatherings and other social events) was mentioned by another $3.9 \%$. Current daily smokers accounted for $22.7 \%(95 \%$ CI'=19.2-26.6) of which $59.5 \%$ were using 
Table 1.Socio-Demographic and Health Characteristics of Participants in Relation to Genders, King Faisal University, Saudi Arabia

\begin{tabular}{|c|c|c|c|}
\hline \multirow[t]{2}{*}{ Characteristics } & \multicolumn{2}{|c|}{ Gender: No. (\%) } & \multirow{2}{*}{$\begin{array}{c}\text { Total }(\mathrm{N}=691) \\
\text { No. }(\%)\end{array}$} \\
\hline & Females $(\mathrm{N}=198)$ & Males (N=493) & \\
\hline Age in years: Median & 38.5 & 40 & 40 \\
\hline Mean \pm SD & $37.5 \pm 8.5$ & $41.9 \pm 10.0$ & $40.4 \pm 9.8$ \\
\hline \multicolumn{4}{|l|}{ Age groups (years): } \\
\hline$<30$ & $31(15.7)$ & $88(17.8)$ & 119(17.2) \\
\hline $30-<40$ & $68(34.3)$ & $126(25.6)$ & 194(28.1) \\
\hline $40-<50$ & $67(33.8)$ & $169(34.3)$ & $236(34.2)$ \\
\hline $50-63$ & $32(16.2)$ & $110(22.3)$ & $142(20.5)$ \\
\hline \multicolumn{4}{|l|}{ Nationality: } \\
\hline Saudis & $167(84.3)$ & $364(73.8)$ & $531(76.8)$ \\
\hline Arabs non Saudi & $31(15.7)$ & $97(19.7)$ & 128(18.6) \\
\hline Non Arabs & -- & $32(6.5)$ & $32(4.6)$ \\
\hline \multicolumn{4}{|l|}{ Residence: } \\
\hline Urban & 167(84.3) & $425(86.2)$ & $592(85.7)$ \\
\hline Rural & $31(15.7)$ & $68(13.8)$ & $99(14.3)$ \\
\hline \multicolumn{4}{|l|}{ Educational status: } \\
\hline Primary/preparatory & $25(12.6)$ & $84(17.0)$ & $109(15.8)$ \\
\hline Secondary & $44(22.2)$ & $166(33.7)$ & $210(30.4)$ \\
\hline College or higher & $129(65.2)$ & 243(49.3) & $372(53.8)$ \\
\hline \multicolumn{4}{|l|}{ Job within the University: } \\
\hline Faculty & $78(39.4)$ & 175(35.5) & 253(36.6) \\
\hline Administrative & $91(46.0)$ & $222(45.0)$ & $313(45.3)$ \\
\hline Technicians & $24(12.1)$ & $77(15.7)$ & 101(14.6) \\
\hline Others! & $5 \quad(2.5)$ & $19(3.8)$ & $24(3.5)$ \\
\hline \multicolumn{4}{|l|}{ Marital status: } \\
\hline Married & 137(69.2) & $418(84.8)$ & $555(80.3)$ \\
\hline Single & $49(24.7)$ & $69(14.0)$ & 118(17.1) \\
\hline Divorced/widowed & $12(6.1)$ & $6 \quad(1.2)$ & $18(2.6)$ \\
\hline \multicolumn{4}{|l|}{ Chronic comorbidities: } \\
\hline Diagnosed hypertension & $34(17.2)$ & $59(12.0)$ & $93(13.5)$ \\
\hline Diagnosed diabetes & $8 \quad(4.0)$ & $56(11.4)$ & $64(9.3)$ \\
\hline Diabetic and hypertensive: & $4 \quad(2.0)$ & $14(2.8)$ & $18(2.6)$ \\
\hline \multicolumn{4}{|c|}{ History of coronary heart disease } \\
\hline & -- & $13(2.6)$ & $13(1.9)$ \\
\hline
\end{tabular}

*SD $=$ Standard deviation. Others includes: agricultural and maintenance engineers, safety an security officers, drivers, and auxiliary workers

cigarettes, $37.4 \%$ were smoking shisha, $3.1 \%$ smoking both. Current smokers were more among $30-<40$ years age group, $75 \%$ of the current daily smokers were Saudis, $18 \%$ were Arab non Saudis, and 7\% non-Arabs. About $52 \%$ of the current smokers were occupying administrative jobs, $17.0 \%$ were faculty and $31.2 \%$ technical and assistant staff. The number of cigarettes smoked/ day was higher among those aged $\geq 40$ years, while the number of shisha bowls/day was more among those aged $\leq 40$ years.

\section{Vegetables and fruits servings/day}

The median (mean) servings of vegetables, fruits and both vegetables $\&$ fruits per day in the last seven days was $2.0($ mean $=1.8, \mathrm{CI}=1.7-2.0), 1.0(0.9, \mathrm{CI}=0.8-1.1)$ and 3.0 (3.9, CI=2.7-3.1) respectively. The median servings of vegetables, fruits and vegetables $\&$ fruits in the last 7 days among men was 2.2 (mean=2.0, $\mathrm{CI}=1.9-2.4)$, $0.5(0.9, \mathrm{CI}=09-1.0)$ and $2.5(2.8, \mathrm{CI}=2.6-3.2)$, higher for vegetables and fruits and vegetables consumption compared to women of $1.0($ mean $=1.3, \mathrm{CI}=1.0-1.5), 1.0$ (1.0, $\mathrm{CI}=0.8-1.3)$ and $2.0(2.3, \mathrm{CI}=1.9-2.6)$ respectively but without statistical difference. Of the sampled population, $95.1 \%, 94.4 \%$ and $86.0 \%$ received $<5$ servings/day of vegetables, fruits and vegetables $\&$ fruits respectively. Only $5.1 \%, 4.9 \%$ and $14 \%$ of participants consumed $\geq 5$ servings /day of vegetables, fruits and fruits and vegetables/day respectively (Figure 1). No significant difference regarding the number of servings of fruits and vegetables/day in relation to age or genders but to nationalities as $16.4 \%$ and $14.1 \%$ of Arab non-
Saudis consumed $\geq 5$ servings of vegetables and fruits/ day compared to Saudis (only $2.1 \%$ and $2.2 \%$ consumed $\geq 5$ servings of vegetables and fruits/ day respectively).

\section{Physical activity (PA)}

Figure 2 shows the PA in METs minutes/week in relation to genders. The median total METs minutes/week for all domains was of 1327 (CI for the median=58.8-1329, $\mathrm{IQR}=1097$ ) significantly higher among men (median of 1391, CI=67-1133, IQR=1209), compared to women 1191 $(\mathrm{CI}=24-1211, \mathrm{IQR}=983)(\mathrm{p}=0.012)$. The total work-related METs minutes /week with a median of 908 (CI=31-932, $\mathrm{IQR}=814$ ) more among women (median of 996 compared to men of $788 \mathrm{METs}$ minutes/week). Those aged 30 to $<40$ years of both genders showed the highest work-related METs (median=1410,CI=58-1880 in men and 1184 , $\mathrm{CI}=91-1348$ in women), statistically significant only among men in relation to other age groups, Kruskal Wallis, $\mathrm{p}=0.011)$. Those aged 20 to $<30$ years showed the highest leisure-related PA (median $=668, \mathrm{CI}=121-890$ in men, and 259 ( $\mathrm{CI}=42-279)$ in women, only statistically different among men's age groups (Kruskal Wallis, p=0.003). Communing or transport-related PA accounted for the least METs among both genders (480 METs minute/week in men and 324 METs minutes/week for women). Of the total participants, $3.8 \%$ of participants $(\mathrm{CI}=2.6-5.5)$ were categorized as having high PA level (3.7\% in men vs $4.0 \%$

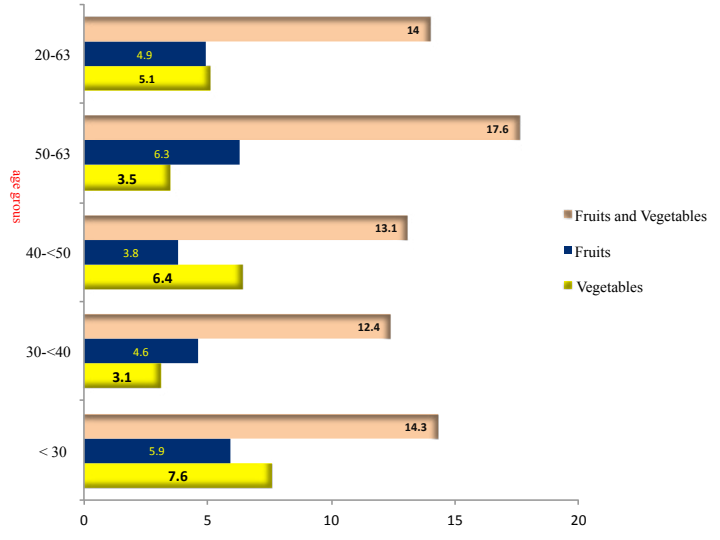

Figure 1. Percentage of $\geq 5$ Servings/day of Fruits and Vegetables among the Sampled King Faisal University Employees in Relation to Age Groups

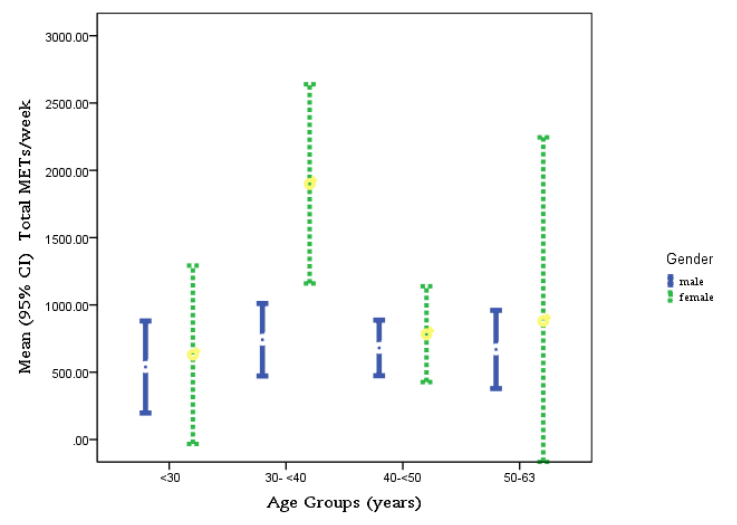

Figure 2. Mean (95\% Confidence Intervals) of Total Metabloic Equivalents (METs Minutes/week) in Relation to Age Groups and Genders among the Sampled King Faisal University Employees 
in women). A total of $160(23.2 \%, \mathrm{CI}=20.1-26.4)$ were in the moderate PA category. Those in the low PA category constituted $73.1 \%$ (CI=69.7-76.3) with no significant differences in relation to gender or age groups. Saudis were more likely to be in the low PA category $(71 \%$ of those with low PA) compared to other nationalities $(68.6 \%$ of Arab non Saudis, and 58.3\% of non Arabs, $\mathrm{p}=0.033$ ). Thirty three percent of non Arabs were in the moderate PA category compared to Saudis and Arab non Saudis (21\% and $27 \%$ respectively). Faculty members were the least active as $76 \%$ of them showed low PA level compared to $67 \%$ of administration staff and $71 \%$ of the technical/ assistant staff.

\section{Overweight and obesity}

Figure 3 displays BMI categories of the studied employees in relation to age groups. The mean total BMI was 28.3(CI=25.8-29.7), higher among women than men (29.1,CI=27.2-30.1 vs 27.8,CI=25.7-29.6 in men). Those with desirable BMI of $<25$ constituted $35.9 \%$ more among men (37.7\% vs $31.3 \%$ of women). Overweight (BMI=2529.9 ) accounted for $33.3 \%$, significantly more among women $38.4 \%$ compared to men $(31.0 \%)(p=0.036)$. Obesity was encountered in $30.7 \%(\mathrm{CI}=27.2-34.1)$. Grade $\mathrm{I}(\mathrm{BMI}=30-34.9)$ and $\mathrm{II}(\mathrm{BMI} \geq 35)$ were found in $18.2 \%$

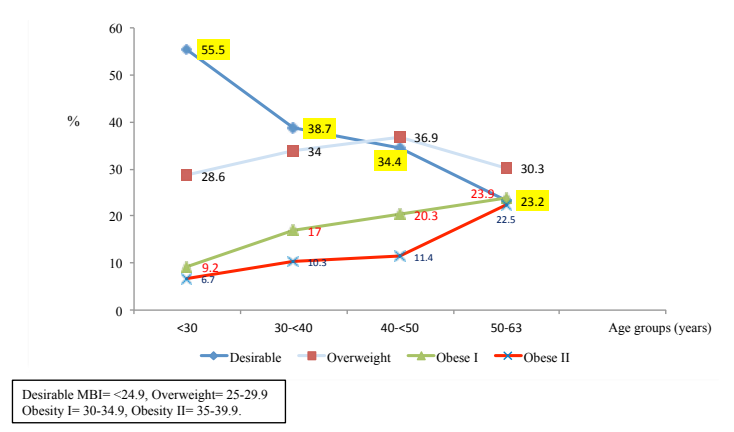

Figure 3. Body Mass Index Distribution by Age Groups among the Sampled King Faisal University Employees and $12.3 \%$ of the studied population respectively with a significant increased trend of grade I obesity in relation to age in both genders. More than $80 \%$ of obese individuals were Saudis, $17.2 \%$ were Arab non-Saudis and $2.1 \%$ were non Arabs. Obesity was more among administrative staff $(60.0 \%)$ followed by faculties $(20.4 \%)$, then technical and other jobs (19.6\%). The mean waist circumference (WC) in men was $101.9 \pm 16.4 \mathrm{~cm}(\mathrm{CI}=98.5-105.2)$, and $40.0 \%$ of men had a WC $>102 \mathrm{~cm}$. The mean WC in women was $91.7 \pm 16.5 \mathrm{~cm}(\mathrm{CI}=89.4-101.8)$ and $46.5 \%$ of women had a $\mathrm{WC}>88 \mathrm{~cm}$.

\section{Hypertension and elevated blood glucose}

Table 2 displays the mean systolic and diastolic blood pressure among participants in relation to genders and age. Those with a history of HTN constituted $16.1 \%$ (15.2\% of men $v s 18.2 \%$ of women). New cases with systolic HTN $(\geq 140 \mathrm{mmHg}$ ) were detected in $6.5 \%$, diastolic HTN $(\geq 90 \mathrm{~mm})$ in $4.9 \%$ and systolic \& diastolic HTN $(\geq 140 / 90 \mathrm{mmHg})$ in another $6.1 \%$. Overall, $22.5 \%$ of men and $21.2 \%$ of women had HTN (previously diagnosed and those newly detected during the study). Table 7 also depicts the mean FBG among participants by age groups and genders, $14.2 \%$ were found to have $\mathrm{FBG} \geq 110 \mathrm{mg} / \mathrm{dl}$, more among men $(16.8 \%$ vs $7.4 \%$ in women, $\mathrm{p}=0.006)$. A total of 69 (9.9\%) participants had fasting blood sugar $>126 \mathrm{mg} / \mathrm{dl}$ and not diagnosed before as having diabetes $55(11.2 \%)$ men and $14(7.1 \%)$ women.

\section{Lipid profile}

Table 3 demonstrates the mean levels of cholesterol, high density lipoproteins and triglycerides in relation to genders and age groups. For cholesterol, 21.3\% had borderline high $(\geq 190 \mathrm{mg} / \mathrm{dl})$ and $15.3 \%$ had high levels $(\geq 240 \mathrm{mg} / \mathrm{dl})$. Borderline high level was found in $21.3 \%$ of men and $21.2 \%$ of women, while high cholesterol was significantly more in women $(20.2 \%)$ than men $(13.4 \%)$ $(\mathrm{p}=0.014)$. Low high density lipoproteins (HDL) $(<50 \mathrm{mg} /$

Table 2. Blood Pressure Measurements, Hypertension, Elevated Blood Pressure and Blood Glucose Measurements among the Participants. King Faisal University, Saudi Arabia

\begin{tabular}{|c|c|c|c|c|c|c|c|c|c|}
\hline \multirow[t]{2}{*}{$\begin{array}{l}\text { Age groups } \\
\text { and gender }\end{array}$} & \multirow[t]{2}{*}{$\begin{array}{c}\text { Systolic } \\
\text { Mean }(95 \% \mathrm{CI})\end{array}$} & \multirow{2}{*}{$\begin{array}{c}\text { Diastolic } \\
\text { Mean }(95 \% \mathrm{CI})\end{array}$} & \multirow{2}{*}{$\begin{array}{c}\text { Diagnosed } \\
\text { hypertension } \\
\text { No. }(\%)\end{array}$} & \multicolumn{3}{|c|}{$\begin{array}{c}\text { Hypertension: } \\
\text { at screening No. }(\%)\end{array}$} & \multirow[t]{2}{*}{$\begin{array}{c}\text { Blood sugar } \\
\text { Mean }(95 \% \mathrm{CI})\end{array}$} & \multicolumn{2}{|c|}{$\begin{array}{c}\text { Fasting blood sugar: } \\
\text { No. }(\%)\end{array}$} \\
\hline & & & & Both & Systolic & Diastolic & & $\begin{array}{l}\text { aised blood } \\
\text { sugar* }\end{array}$ & $\begin{array}{c}\text { Diagnosed } \\
\text { diabetes }\end{array}$ \\
\hline \multicolumn{10}{|l|}{$\operatorname{Men}(\mathrm{N}=493)$} \\
\hline $20-<30 \quad[n=88]$ & $111.3(101.8-120.7)$ & $73.8(64.9-82.6)$ & $1(1.1)$ & $4(4.5)$ & $4(4.5)$ & $4(4.4)$ & $86.9(79.8-94.0)$ & $3(3.4)$ & $2(2.3)$ \\
\hline $30-<40[n=126]$ & $120.0(115.1-124.9)$ & $80.6(77.4-83.7)$ & $16(18.2)$ & $9(10.2)$ & $7(8.0)$ & $5(5.7)$ & $93.3(85.4-101.2)$ & $13(10.3)$ & $10(7.9)$ \\
\hline $40-<50[n=169]$ & $120.3(116.7-123.9)$ & $81.6(78.6-84.7)$ & $37(29.4) \quad 1$ & $10(7.9)$ & $8(6.3)$ & $16(12.7)$ & $97.1(90.6-103.7)$ & $34(20.1)$ & $29(17.2)$ \\
\hline $50-63 \quad[n=110]$ & $126.3(119.7-132.8)$ & $83.7(77.8-90.4)$ & $21(19.0) \quad 1$ & $13(11.8)$ & $10(9.1)$ & $12(10.9)$ & 108.5(95.9-111.0) & $33(30.0)$ & $27(24.5)$ \\
\hline Total & $123.3(121.9-124.9)$ & $79.2(78.2-83.3)$ & $75(15.2) \quad 3$ & $36(7.3)$ & $29(5.9)$ & $37(7.5)$ & $100.7(95.7-105.7)$ & $83(16.8)$ & $68(13.8)$ \\
\hline \multicolumn{10}{|l|}{ Women (N=198) } \\
\hline $20-<30 \quad[n=31]$ & $114.8(112.2-117.4)$ & 69.1(67.4-70.8) & $1(3.2)$ & - & - & - & $76.5(72.5-80.6)$ & - & - \\
\hline $30-<40[n=68]$ & $121.6(117.0-126.1)$ & $77.9(73.3-82.6)$ & $6(8.8)$ & $2(2.9)$ & - & - & $82.1(75.6-88.6)$ & $3(4.4)$ & $3(4.4)$ \\
\hline $40-<50[n=67]$ & $123.9(119.5-128.4)$ & $79.2(75.7-82.8)$ & $16(23.9)$ & $1(1.5)$ & $5(7.5)$ & $8(11.9)$ & $81.1(73.8-88.4)$ & $6(9.0)$ & $8(11.9)$ \\
\hline $50-63 \quad[n=32]$ & $125.9(119.9-131.8)$ & $74.9(70.9-78.8)$ & $13(40.6)$ & $3(9.4)$ & - & - & $100.5(65.3-135.7)$ & $6(28.1)$ & $1(3.1)$ \\
\hline Total & $121.2(118.8-123.6)$ & $76.2(74.0-78.4)$ & $36(18.2)$ & $6(3.0)$ & $5(2.5)$ & $8(4.0)$ & $81.8(77.6-86.3)$ & $15(7.4)$ & $12(6.1)$ \\
\hline \multicolumn{10}{|l|}{ Total $(\mathrm{N}=691)$} \\
\hline $20-<30 \quad[\mathrm{n}=119]$ & $111.3(101.8-120.4)$ & $73.8(64.9-82.6)$ & $2(1.7)$ & $4(3.4)$ & $4(3.4)$ & $4(3.4)$ & $83.8(78.6-88.9)$ & $3(2.5)$ & $2(1.7)$ \\
\hline $30-<40[n=194]$ & $120.0(115.1-124.9)$ & $80.6(77.4-83.7)$ & $22(11.3)$ & $11(5.7)$ & $7(3.6)$ & $5(2.6)$ & $90.1(84.2-96.1)$ & $16(8.2)$ & $13(6.7)$ \\
\hline $40-<50[n=236]$ & $120.3(116.7-123.9)$ & $81.6(78.6-84.7)$ & $53(22.5)$ & $11(4.7)$ & $13(5.5)$ & $24(10.2)$ & $93.8(84.3-99.2)$ & $40(16.9)$ & $37(15.7)$ \\
\hline $50-63 \quad[n=142]$ & $126.3(119.7-132.8)$ & $83.8(77.1-90.1)$ & $34(23.9) \quad 1$ & $16(11.3)$ & $10(7.0)$ & $12(8.5)$ & $106.8(105.1-128.5)$ & $39(27.5)$ & $28(19.7)$ \\
\hline Total & $120.0(121.8-127.1)$ & $80.0(77.5-81.4)$ & 111(16.1) & $42(6.1)$ & $34(4.9)$ & $45(6.5)$ & $86.0(92.0-99.9)$ & $98(14.2)$ & $80(11.6)$ \\
\hline
\end{tabular}

*Systolic hypertension $=\geq 140 \mathrm{mmHg}$, diastolic hypertension $=\geq 90 \mathrm{mmHg}$.* Fasting blood sugar $\geq 110 \mathrm{mg} / \mathrm{dl}$ 
Table 3. Lipid Profile of the Surveyed King Faisal University's Employees in Relation to Age Groups and Gender

\begin{tabular}{|c|c|c|c|c|c|c|c|c|}
\hline \multirow[t]{2}{*}{$\begin{array}{l}\text { Age groupsr } \\
\text { and gende }\end{array}$} & \multirow[t]{2}{*}{$\begin{array}{l}\text { Total cholesterol } \\
\text { Mean }(95 \% \mathrm{CI})\end{array}$} & \multicolumn{2}{|c|}{$\begin{array}{c}\text { Cholesterol levela: } \\
\text { No. }(\%)\end{array}$} & \multirow{2}{*}{$\begin{array}{l}\text { High Density } \\
\text { lipoproteins* } \\
\text { Mean }(95 \% \mathrm{CI})\end{array}$} & \multirow{2}{*}{$\begin{array}{c}\text { Low HDL } \text { HD }^{\mathrm{b}} \\
\text { levels } \\
\text { No. }(\%)\end{array}$} & \multirow[t]{2}{*}{$\begin{array}{l}\text { Triglycerides } \\
\text { Mean }(95 \% \mathrm{CI})\end{array}$} & \multicolumn{2}{|c|}{$\begin{array}{c}\text { Triglycerides level } \\
\text { : No. }(\%)\end{array}$} \\
\hline & & High & Borderline & & & & High & Borderline \\
\hline \multicolumn{9}{|l|}{$\operatorname{Men}(\mathrm{N}=493)$} \\
\hline $20-<30 \quad[\mathrm{n}=88]$ & $172.7(162.2-183.3)$ & $6(6.8)$ & $9(10.2)$ & $56.3(48.9-73.7)$ & $14(15.9)$ & $127.4(106.5-148.3)$ & $7(8.0)$ & $26(29.5)$ \\
\hline $30-<40[n=126]$ & $176.9(168.6-185.1)$ & 11(8.7) & $32(25.4)$ & $54.7(49.6-69.9)$ & $32(25.4)$ & $136.3(116.6-242.2)$ & $17(13.5)$ & $28(22.2)$ \\
\hline $40-<50[n=169]$ & $181.0(174.7-187.3)$ & $28(16.7)$ & $38(22.5)$ & $45.8(38.9-62.6)$ & $82(48.5)$ & $130.7(115.4-145.9)$ & $21(12.4)$ & $32(18.9)$ \\
\hline $50-63 \quad[n=110]$ & $181.8(171.5-194.1)$ & $21(19.1)$ & $26(23.6)$ & $42.1(31.1-55.0)$ & $64(58.2)$ & $114.0(99.1-128.8)$ & $9(8.2)$ & $18(16.4)$ \\
\hline Total & $178.9(174.5-186.5)$ & $66(13.4)$ & $105(21.3)$ & $45.5 .8(40.9-64.7)$ & 192(38.9) & $126.8(118.4-135.2)$ & $54(11.0)$ & $104(21.1)$ \\
\hline \multicolumn{9}{|l|}{ Women (N=198) } \\
\hline $20-<30 \quad[\mathrm{n}=31]$ & $173.6(153.4-193.8)$ & $3(9.7)$ & 6(19.4) & $63.2(34.6-71.8)$ & $7(22.6)$ & $148.0(133.8-232.2)$ & $7(22.6)$ & $7(22.6)$ \\
\hline $30-<40[n=68]$ & $212.3(168.6-231.3)$ & $19(27.9)$ & $13(19.1)$ & $44.5(36.2-54.7)$ & $32(47.1)$ & $191.7(159.4-263.0)$ & $29(42.6)$ & $21(30.9)$ \\
\hline $40-<50[n=67]$ & $182.8(171.5-194.1)$ & $10(14.9)$ & $18(26.9)$ & $41.5(38.2-44.8)$ & $14(20.9)$ & $145.4(108.6-182.1)$ & $7(10.4)$ & $13(19.4)$ \\
\hline $50-63 \quad[n=32]$ & $187.4(158.9-215.8)$ & $8(25.0)$ & $5(15.6)$ & $62.5(26.6-78.9)$ & $9(28.1)$ & $119.1(67.0-171.2)$ & $3(9.4)$ & $4(12.5)$ \\
\hline Total & $191.4(82.1-200.7)$ & $40(20.2)$ & $42(21.2)$ & $51.8(42.2-59.0)$ & $62(31.3)$ & $169.8(142.3-197.8)$ & $46(23.2)$ & $45(22.7)$ \\
\hline
\end{tabular}
high $=\geq 180 \mathrm{mg} / \mathrm{dl}$

Table 4. Clustering of Non Communicable Diseases Risk Factors in Relation to Genders of the Studied King Faisal University' Employees

\begin{tabular}{|c|c|c|c|c|c|c|c|c|c|c|c|}
\hline \multirow[t]{2}{*}{ Risk factors \# } & \multirow[t]{2}{*}{$\mathrm{P}$} & \multirow[t]{2}{*}{$\mathrm{S}$} & \multirow[t]{2}{*}{$\mathrm{O}$} & \multirow[t]{2}{*}{$\mathrm{F} / \mathrm{V}$} & \multirow[t]{2}{*}{ HTN } & \multirow[t]{2}{*}{$\mathrm{Sg}$} & \multirow[t]{2}{*}{ Dys* } & \multirow[b]{2}{*}{ Women $(n=198)$} & \multicolumn{2}{|c|}{ Distribution: No. $(\%)$} & \multirow[t]{2}{*}{ Pvalue* } \\
\hline & & & & & & & & & $\operatorname{Men}(n=493)$ & Total $(n=691)$ & \\
\hline 7 & + & + & + & + & + & + & + & -- & $19(3.9)$ & $19(2.7)$ & $\overline{--}$ \\
\hline 6 & + & + & + & + & + & - & + & -- & $6(1.2)$ & $6(0.9)$ & -- \\
\hline 6 & + & + & + & + & - & + & + & -- & $6(1.2)$ & $6(0.9)$ & -- \\
\hline 6 & + & - & + & + & + & + & + & $10(5.1)$ & $2(0.4)$ & $12(1.7)$ & 0.001 \\
\hline 6 & + & + & + & + & + & + & - & -- & $10(2.0)$ & $12(1.7)$ & -- \\
\hline Total & & & & & & & & $10(5.1)$ & $26(4.5)$ & $36(5.2)$ & 0.532 \\
\hline 5 & + & + & - & + & + & + & - & -- & $12(2.4)$ & $12(1.7)$ & -- \\
\hline 5 & + & - & + & + & + & - & + & $6(3.0)$ & $12(2.4)$ & $18(2.6)$ & 0.417 \\
\hline 5 & - & - & + & + & + & + & + & $5(2.5)$ & $3(0.6)$ & $8(1.2)$ & 0.047 \\
\hline Total & & & & & & & & $11(5.6)$ & $27(5.5)$ & $38(5.5)$ & 0.552 \\
\hline 4 & + & + & + & + & - & - & + & -- & $12(2.4)$ & $12(1.7)$ & -- \\
\hline 4 & + & + & + & - & + & - & - & -- & $6(1.2)$ & $6(0.9)$ & -- \\
\hline 4 & + & + & + & + & - & - & - & -- & $10(2.0)$ & $10(1.4)$ & -- \\
\hline 4 & + & + & - & + & + & - & - & -- & $4(0.8)$ & $4(0.6)$ & -- \\
\hline 4 & + & - & + & - & + & & + & $6(3.0)$ & $13(2.6)$ & $19(2.7)$ & 0.477 \\
\hline 4 & + & - & + & + & - & + & - & $5(2.5)$ & $11(2.2)$ & $16(2.3$ & 0.506 \\
\hline 4 & + & - & + & + & + & - & - & $7(3.5)$ & $11(2.2)$ & $18(2.6)$ & 0.236 \\
\hline 4 & + & - & + & + & - & - & + & $8(4.0)$ & $12(2.4)$ & $20(2.9)$ & 0.187 \\
\hline 4 & + & - & + & + & + & - & - & $5(2.5)$ & $6(1.2)$ & $11(1.6)$ & 0.023 \\
\hline 4 & - & + & + & + & - & - & + & -- & $6(1.2)$ & $6(0.9)$ & -- \\
\hline 4 & - & - & + & + & + & + & - & $4(2.0)$ & $4(0.8)$ & $8(1.2)$ & 0.17 \\
\hline 4 & - & - & + & + & + & - & + & $4(2.0)$ & $2(0.4)$ & $6(0.9)$ & 0.06 \\
\hline Total & & & & & & & & $39(19.6)$ & $97(19.7)$ & $136(19.7)$ & $0.538 * *$ \\
\hline 3 & + & - & + & + & - & - & - & $9(4.5)$ & $57(11.6)$ & $66(9.6)$ & 0.002 \\
\hline 3 & + & - & - & + & - & - & + & $4(2.0)$ & $9(1.8)$ & 13(1.9) & 0.54 \\
\hline 3 & - & - & + & - & + & - & + & $7(3.5)$ & -- & $7(1.0)$ & -- \\
\hline 3 & - & + & - & + & - & - & + & -- & $5(1.0)$ & $5(0.7)$ & -- \\
\hline 3 & - & - & + & + & + & - & - & $4(2.0)$ & $11(2.2)$ & $15(2.2)$ & 0.559 \\
\hline 3 & - & - & + & + & - & + & - & $8(4.0)$ & $13(2.6)$ & $21(3.0)$ & 0.231 \\
\hline 3 & - & - & + & + & - & - & + & $5(2.5)$ & $37(7.5)$ & $42(6.1)$ & 0.007 \\
\hline Total & & & & & & & & $37(18.7)$ & $132(26.8)$ & $169(24.5)$ & $0.014 * *$ \\
\hline
\end{tabular}

*Fisher Exact, **Chi square for independent samples. p= Physical inactivity of $<600 \mathrm{METS} /$ minute/week, $\mathrm{S}=$ current daily smoking, $\mathrm{O}=$ obesity with BMI $>29.9, \mathrm{~F} / \mathrm{V}=$ low consumption of fruits and vegetables $<5$ servings/day, HTN= hypertension $>140 / 90 \mathrm{mmHg}, \mathrm{Sg}=$ fasting blood sugar $>126 \mathrm{mg} / \mathrm{dl}$, Dys** the presence of dyslipidemia included cholesterol $\geq 240 \mathrm{mg} / \mathrm{dl}$, triglycerides of $\geq 180 \mathrm{mg} /$ $\mathrm{dl}$ and/or low high density lipoproteins $<50 \mathrm{mg} / \mathrm{dl}$ for men and $<40 \mathrm{mg} / \mathrm{dl}$ for women)

dl for men) was encountered in $38.9 \%$ with significant downward trend in relation to age $(\mathrm{p}=0.012)$, while among women low HDL $(<40 \mathrm{mg} / \mathrm{dl})$ was encountered in $31.3 \%$. Total subjects with low HDL accounted for 254(36.8\%). Triglycerides (TG) was borderline high $(\geq 150 \mathrm{mg} / \mathrm{dl})$ in $149(21.6 \%)$ and high $(\geq 180 \mathrm{mg} / \mathrm{dl})$ in $100(14.5 \%)$. Elevated TG levels was detected in $32 \%$ of men and $46.0 \%$ of women $(\mathrm{p}=0001)$.

\section{Clustering of NCDs risk factors}

Figure 4 displays the distribution of risk factors in relation to genders, 19 men $(2.7 \%$ of total and $3.9 \%$ of men) had seven risk factors, $36(5.2 \%)$, [26 men (4.5\%) and 10 women (5.1\%)] with 6 risk factors, $38(5.5 \%)$, [27 men $(5.5 \%)$ and 11 women (5.6\%)] with 5, $136(19.7 \%)$, [97 men and 39 women] with 4 factors and $169(24.5 \%)$, [132 men and 37 women] with 3 (more in men 28.8\% vs $18.7 \%$ in women), over all, 301 men (61.1\%) and 97 women $(49.0 \%)$ had $\geq 3$ risk factors. Those with two risk factors constituted $240(34.7 \%)$, [173 men (35.1\%) and 67 women $(33.8 \%)$ ], $32(4.6 \%)$ had one risk factor ( $3.4 \%$ men and $7.5 \%$ women). Only $21(3.0 \%)$ of the 


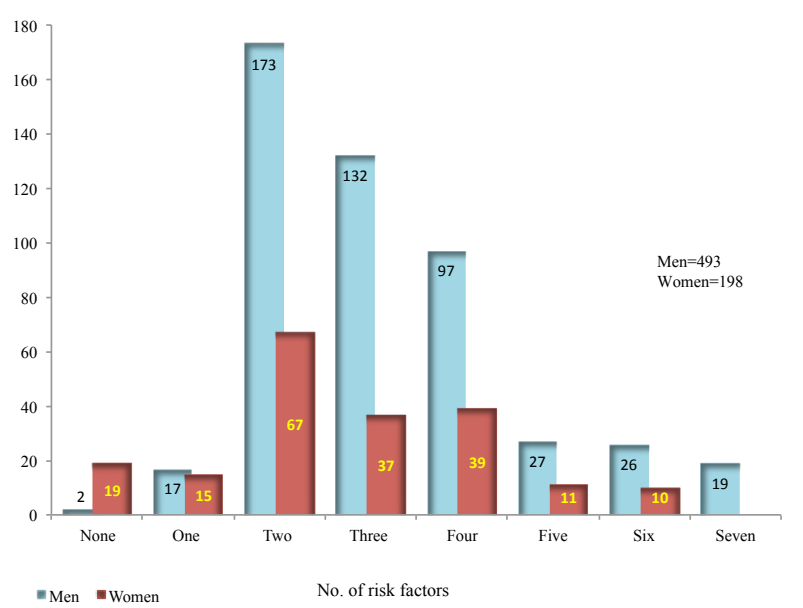

Figure 4. Number of Non-Communicable Diseases Risk Factors among King Faisal University Emplyees Distributed by Genders

Table 5. Univariate and multivariate analysis of correlates for clustering of the non communicable risk factors among employees at King Faisal University

\begin{tabular}{|c|c|c|c|}
\hline \multirow{2}{*}{ Independent variables } & \multicolumn{2}{|c|}{ Risk factors: No. (\%) } & \multirow{2}{*}{$\begin{array}{l}\text { Univariate analysis } \\
\text { Odds ratio }(95 \% \mathrm{CI})\end{array}$} \\
\hline & $\geq 3(\mathrm{~N}=398)$ & $<3(\mathrm{~N}=293)$ & \\
\hline \multicolumn{4}{|l|}{ Age groups (years): } \\
\hline$<30$ & $42(10.6)$ & $56(19.1)$ & Reference \\
\hline $30-<40$ & $83(20.9)$ & 111(37.9) & $0.50(0.32-0.85)^{* *}$ \\
\hline $40-<50$ & $147(36.9)$ & $89(30.4)$ & $1.34(0.98-1.85)$ \\
\hline $50-63$ & $126(31.6)$ & $37(12.6)$ & $3.21(2.14-4.80)^{* *}$ \\
\hline \multicolumn{4}{|l|}{ Gender: } \\
\hline Women & $97(24.4)$ & $101(34.5)$ & Reference \\
\hline Men & $301(75.6)$ & $192(65.5)$ & $1.63(1.17-2.28)^{*}$ \\
\hline \multicolumn{4}{|l|}{ Nationality: } \\
\hline Non Arabs & $18(4.6)$ & $14(4.8)$ & Reference \\
\hline Saudis & $301(75.6)$ & $230(78.5)$ & $0.85(0.60-1.22)$ \\
\hline Arab non Saudis & $79(19.8)$ & 49(16.7) & $0.94(0.46-1.12)$ \\
\hline \multicolumn{4}{|l|}{ Residence: } \\
\hline Rural & $57(14.3)$ & $42(14.3)$ & Reference \\
\hline Urban & $341(85.7)$ & 251(85.7) & $1.00(0.65-1.54)$ \\
\hline \multicolumn{4}{|l|}{ Educational status } \\
\hline Primary/preparatory & $56(14.1)$ & $53(18.1)$ & Reference \\
\hline Secondary & $141(35.4)$ & $69(23.5)$ & $1.78(1.27-2.50)^{* *}$ \\
\hline College or higher & $201(50.5)$ & $171(58.4)$ & $0.73(0.54-0.98)^{*}$ \\
\hline \multicolumn{4}{|c|}{ Job within the University } \\
\hline Faculty & $136(34.2)$ & 117(39.9) & Reference \\
\hline Administrative & $186(46.7)$ & $127(43.3)$ & $1.15(0.84-1.55)$ \\
\hline Technicians and other & rs $76(19.1)$ & $49(16.7)$ & $1.17(0.79-1.75)$ \\
\hline \multicolumn{4}{|c|}{ Comorbidties: } \\
\hline Hypertension & $34(8.5)$ & $15(5.1)$ & $1.73(0.92-3.24)$ \\
\hline Diabetes & $34(8.5)$ & $22(7.5)$ & $1.15(0.66-2.01)$ \\
\hline \multicolumn{4}{|l|}{ Smoking status: } \\
\hline Never & $279(70.1)$ & 234(79.9) & Reference \\
\hline Current smokers & $97(24.4)$ & 34(11.6) & $2.45(1.61-3.75)^{* *}$ \\
\hline Ex smokers & $22(5.5)$ & $25(8.5)$ & $0.63(0.35-1.14)$ \\
\hline \multicolumn{4}{|l|}{ Body mass index: } \\
\hline Lean/desirable & $56(14.1)$ & $192(65.5)$ & Reference \\
\hline Overweight & 159(39.9) & $71(24.2)$ & $2.08(1.49-2.91)^{*}$ \\
\hline Obese & 183(46.0) & $30(10.2)$ & $7.46(4.87-11.41)^{* *}$ \\
\hline \multicolumn{4}{|c|}{ Physical activity levels: } \\
\hline High & $6(1.5)$ & 20(6.9) & Reference \\
\hline Moderate & $49(12.3)$ & 111(37.9) & $1.96(1.35-2.86)^{*}$ \\
\hline Low & $343(86.2)$ & $162(55.3)$ & $5.04(3.49-7.27)^{* *}$ \\
\hline
\end{tabular}

* $\mathrm{Cl}=$ Confidence intervals. $* \mathrm{p}<0.05, * * \mathrm{p}<0.001$, Adjusted for other independent variables in the model. For the multivariate logistic regression model: percent predicted $=76.1$, constant $=1.293$, Hosmer and Lameshow test: Chi-square $=6.042, p=0.642$. Risk factors included: obesity (body mass index $<29.9)$, current daily smoking, insufficient vegetables and fruits servings $(<5$ serving day), physical inactivity ( $<150$ minutes/week), hypertension (blood pressure $>140 / 90 \mathrm{mmHg}$ ), elevated blood sugar level ( $>126 \mathrm{mg} / \mathrm{dl})$, and dyslipidemia (triglycerides $>180 \mathrm{mg} / \mathrm{dl}$ and high density lipoproteins) sampled population had no risk factors (two men and 19 women). Table 4 demonstrates the clustering of risk factors $(\geq 3)$ in relation to genders. Physical inactivity, smoking (in men), obesity and insufficient intake were predominant risk factors encountered along different categories of combinations. Those with combinations of $\geq 6$ risk factors, behavioral risk factors namely physical inactivity, smoking (in men), obesity, insufficient intake of vegetables and fruits were consistently found among men, while women showed significant combination of the physical factors and dyslipidemia than men. Table 5 shows the results of univariate analysis and multivariate logistic regression model of the independent variables that potentially favor clustering of NCDs risk factors.

Multivariate logistic regression model showed that gender (men, adjusted Odds ratio ' $\mathrm{aOR}$ ' $=1.51, \mathrm{CI}=1.11$ $2.14)$, aged $\geq 50$ years $(\mathrm{aOR}=3.06, \mathrm{CI}=1.99-4.72)$, with<college education $(\mathrm{aOR}=1.75, \mathrm{CI}=1.20-2.47)$, current daily smokers $(\mathrm{aOR}=2.37, \mathrm{CI}=1.58-3.58)$, obese $(\mathrm{aOR}=6.96, \mathrm{CI}=4.55-10.63)$ and low PA level $(\mathrm{aOR}=4.59$, $\mathrm{CI}=3.03-6.98$ ) were the significant positive predictors for the clustering of risk factors. Residence, nature of job within the University's, nationality, and the presence of previously diagnosed chronic diseases (diabetes, HTN) had no influence on risk factors clustering among the studied sample.

\section{Discussion}

This cross-sectional study although not representative yet provided a detailed description of the prevalence of behavioral and biochemical NCDs risk factors. This study revealed that daily smokers accounted for $22.7 \%$, with $94.9 \%, 95.1 \%$ and $86 \%$ consumed $<5$ servings per day of vegetables, fruits and both fruits and vegetables/day respectively, $73 \%$ were physically inactive, $64 \%$ were overweight or obese, $22.1 \%$ with HTN, $21.5 \%$ diabetics Elevated Cholesterol level was found in $36.6 \%$, low high density lipoproteins in $36.8 \%$, and elevated triglycerides in $36.1 \%$.

Our results are comparable to those reported from a South African study where employees from 68 companies were included and it was found that $67 \%$ were physically inactive, $62 \%$ were either overweight or obese and $71 \%$ consumed<five servings of fruit and vegetables/ day, $38 \%$ were smokers, one third had blood pressure $>140 / 90 \mathrm{mmHg}$, and $41 \%$ had cholesterol values more than $5.2 \mathrm{mmol} / \mathrm{l}$ and only $17 \%$ had fewer than 2 risk factors and the most prevalent number of risk factors was 3 , which was found in $32 \%$ (Kolbe-Alexander et al,. 2013). On the contrary, our study revealed that only $3 \%$ had no NCDs risk factors, while 398 (57.6\%) had $\geq 3$ NCDs risk factors. In a Brazilian study, the prevalence of smoking, excessive alcohol consumption and irregular fruits intake was higher in men, whereas a larger proportion of women exhibited leisure-time PinA, $26.1 \%$ of women and $18.9 \%$ of men displayed no risk factors, while $43 \%$ of men and $36.6 \%$ of women had two or more risk factors (de Costa et al., 2013), in the current study, except for smoking which was exclusive to men and overweight/obesity which showed 
predominance among women, there was no differences in prevalence of other NCDs risk factors, moreover our results demonstrated a greater clustering of NCDs risk factors than the previous studies.

Also this study revealed as others (de Costa et al., 2013; Kolbe-Alexander et al., 2013) that the behavioral NCDs risk factors namely PinA, smoking, obesity and insufficient intake of vegetables and fruits were the predominant factors encountered. These environmental and behavioral risk factors made an important contribution to the global cancer burden (WHO, 2010). However, the magnitude of the effect of these risk factors on cancer control will depend on their prevalence and the direction of their time trends, both of which are on the rise in Saudi Arabia (W.H.O., 2012). These results suggested that employees are at increased risk for NCDs and they would benefit from worksite health promotion programs specially tackling modifiable risk factors.

The worksite has been shown to be a favorable setting to implement intervention programs aiming to reduce the risk for and prevalence of NCD's, as many individuals can be reached at the same time (Plotnikoff et al., 2005). These programs have been shown to play a role in improving health status and lifestyle behaviors, such as increased PA and reduced dietary fat intake among employees (Serxner et al., 2003). In this study $26.6 \%$ of were currently daily smokers and exclusively limited to men, which is consistent with findings reported previously using STEPS survey in 2005 (Saudi Arabia STEPS Report, 2005) where $24.7 \%$ of men were current smokers. However; unlike the current study, the percentage of women smokers was $1.4 \%$, this difference may be attributed to the small sample of women included and different socio-demographic characters of participants especially relevant to health awareness.

The current study also revealed that only $5.1 \%$, $4.9 \%$ and $14 \%$ of participants consumed $\geq 5$ servings/ day of vegetables, fruits and both fruits and vegetables/ day respectively. A diet rich in vegetables and fruits has beneficial health effects including decrease in the likelihood of having a heart attack or stroke and possibly protect against some types of cancers (Wisemann, 2008). Globally, food habits have become poorer during the last three decades (F.A.O/W.H.O., 2006) and there has been a drastic change in food consumption patterns in the Arab Gulf countries. The structure of diet has shifted towards a high-energy-density with more fat, salt and added sugar, and with decline in the intake of fruit, vegetables, whole grains, and legumes (Musaiger et al., 2011). Saudi Arabia is one of six Arab countries where 79-96\% of adults eat $<5$ servings of fruit and vegetables/ day (W.H.O., 2010). Fruits consumption provides a protective effect against several types of cancer.

Examination of NCDs risk factor data of 89,404 Iranian individuals aged 15-64 years through an ecological study showed that breast cancer incidence had a significant positive relationship with the occurrence of diabetes mellitus, low fish consumption, and non-consumption of fruit, and academic educational status of the included women (Abbastabar et al., 2013). Although the results should be interpreted with caution, these findings and ours are highlighting the likelihood of risk for breast cancer among employees of academic institutions. In addition, several studies have reported the positive relationship between breast cancer incidences and diabetes mellitus (Alegre, 2013; Kruk, 2013).

Another important NCDs risk factor is the PA, this study revealed that $73.1 \%$ of the participants were categorized as being of low PA, higher figures than those reported from community-based studies (Saudi Arabia STEPS Report, 2005; Al-Nozha et al 2007; Al-Hazzaa 2007; Amin et al; 2011; Amin et al 2012) this difference could be explained partially by different age structure of the studied group and the sedentary nature of their jobs within the university. Research has shown that PA has a beneficial health effect and is essential means for prevention of many NCDs including cancers (Custs, 2011; Leitzmann, 2011). PinA is the most influential factor contributing to the high rates of obesity in Arab societies (Musaiger et al., 2012) and it was found that both PinA and greater BMI are modifiable risk factors for colon cancer in both Western and Asian populations (Morrison et al., 2013). In this study, $33.3 \%$ were overweight and $38.4 \%$ were obese. The prevalence of overweight and obesity in Arab countries has reached an alarming level, among adults ranging between $40-60 \%$ for men and 50$70 \%$ for women (Musaiger et al., 2007). Rapid changes in dietary habits, lifestyle, and PinA have led to an increase in the prevalence of overweight and obesity in Arab countries with consequent increase in NCDs prevalence (Musaiger et al., 2012). In the current study, the number of overweight women was significantly higher than men while obesity had no significant difference in relation to genders. This finding is different from other study in the Gulf countries, where the prevalence of overweight was higher among men, while that of obesity was higher among women (Musaiger et al., 2012). In this study both previously diagnosed and newly discovered hypertensives constituted $22.2 \%$ and new hypertensive cases were detected in $6.1 \%$. The rates of HTN and diabetes in the Gulf region including Saudi Arabia appear to be some of the highest in the world (Keaney et al., 2004) and more than one fourth of the adult Saudi population suffers from HTN (Al Nozha et al., 2007). A prevalence of $26 \%$ was reported out of the Saudi STEPS survey in 2005 with more women affection (Saudi Arabia STEP Report, 2005), yet a lower rate of HTN of $9.2 \%$ was reported by similar study conducted among King Khalid University personnel in Bisha (Ramadan et al., 2013). In the current study $11.6 \%$ were previously diagnosed as diabetics. Diabetes prevalence in Saudi Arabia was found to be $\approx 18 \%$ (Saudi Arabia STEP Report, 2005). It is worth mentioning that during this survey, $6.1 \%$ and $9.9 \%$ were newly diagnosed cases of HTN and diabetes respectively without being previously aware of their conditions.

These findings highlight the necessity for screening programs for early case detection and as initial platform for health education initiatives for NCDs prevention. Dyslipidemia is an important risk factor for many NCDs (Al-Kaabba et al., 2012) and there is some evidence of its association is associated with some cancers (Jafri and Karas, 2010). In this study, high TG and total cholesterol 
levels were detected in $32 \%$ and $36.6 \%$ respectively. Women had statistically significant higher levels of total cholesterol and TG than men. Low HDL was detected in $36.8 \%$ of participants. The results of the current study are in agreement with a previous study conducted in Saudi Arabia where the prevalence of dyslipidemia rate was in the range of 20-44\% (Al-Kaabba et al., 2012), moreover, Saudi Arabia's STEP Report revealed that at least one fifth of the included population had high cholesterol level (Saudi Arabia STEP Report, 2005). Knowledge on the clustering pattern of NCDs risk factors may guide the design of more effective health promotion initiatives (de Costa et al., 2013).

This study provided a detailed description of the different NCDs combinations encountered among the surveyed employees. In their cross-sectional study, de Costa et al in 2013, found that $43 \%$ of men and $36.6 \%$ of women clustered at least two NCDs risk factors, three $(19.2 \%)$ and five $(9.8 \%)$. The results reported by the previous study are far less than we have found but this difference may be attributed to methodological considerations and the number and type (behavioral/ biochemical) of the NCDs risk factors studied. Irrespective of the criteria adopted to classify PAlevel and an unhealthy diet, studies that evaluated simultaneous risk factors found that these two behaviors namely PinA and unhealthy diet were the most prevalent (Schuit et al., 2002; Poortinga, 2007; Moura et al., 2009; de Costa et al., 2013: KolbeAlexander et al., 2013). Another significant clustering pattern in this study was smoking, which was present in many combinations in men contrary to what was found by de Costa and his coworkers in 2013 in Brazil where smoking was more in risk factors combinations among women (de Costa et al., 2013). Considering simultaneous clustering of NCDs risk factors, our findings were similar to other studies conducted in Brazil (de Costa et al., 2013), England (Poortinga, 2007), Denmark (Schuit et al., 2002) and South Africa (Kolbe-Alexander et al., 2013).

One interesting finding revealed from this study was the effect of low PA on clustering of risk factors, where those with low PA were $>4$ folds at risk for having $\geq 3$ NCDs. Kolbe-Alexander and his coworkers found that employees with insufficient PA had a higher number of additional modifiable risk factors for NCD's than those who were meeting PA recommendations (KolbeAlexander et al., 2013). These results are supported by another cross-sectional study (Ekblom-Bak et al., 2010) where the odds for the physically active Swedish participants having $\geq 3$ risk factors were $50 \%$ lower than those who were inactive, even after adjusting for confounders. Furthermore, in the same study, the odds of having additional risk factors, such as hypertension or overweight, were further reduced among the participants with higher levels of cardiovascular fitness (EkblomBak et al., 2010). In our study, men were more likely to exhibit $\geq 3$ NCDs risk factors than women. The same pattern was reported from other studies around the world (Schuit et al., 2002; Poortinga, 2007; Moura et al., 2009). Also, those aged $>50$ years were more at risk for NCDs risk factors clustering; this was in agreement with other studies indicated that advancing age is accompanied by greater clustering of risk factors (Poortinga et al., 2007; de Costa et al., 2013). Moreover, some claimed that higher proportion of smokers and inactive individuals were found among the older subjects which may explain the excessive clustering at older age (Katano et al., 2010).

As in most studies investigated the associations between NCDs risk factors and educational status (Schuit et al 2002; Poortinga, 2007; Muniz et al., 2012; de Costa et al., 2013; Abbastabar et al., 2013) this study confirmed that individuals with $<$ college education tend to cluster and accumulate more risk factors. Suitable means to delivery health education are needed to convey knowledge to the population about chronic diseases. Ministries of Health in many developing countries have introduced and implemented successful health education programs like family planning, immunization services and infection prevention, but those dedicated to NCDs are in the form of health promotion are frequently short term and non sustainable and proved non-effective, health promotion targeting those at middle age should follow new strategies with involvement of all sectors including universities in order for effective and sustainable outcomes.

The results of this study can be viewed within the context of the following limitations: First, the response rate in our study was low (33.0\%). Non-response may be due to the low level of health awareness (or consciousness about one's own health) among university employees. Study participants were either more health conscious, had a suspicion about their wellbeing, or both. Second, in the light of the previous notion, the results of this study may imply over estimation due to inclusion of high risk population during the recruitment phase (those with more risks). Although invitation to participate was forwarded to all employees within the university, the participation was voluntary and those participated are expected to be more health conscious or already have information about their health condition and participated for reassurance. Third, the social desirability would cast shadows on several items including servings of vegetables, fruits, smoking and PA patterns which may result in over/under estimation of these variables. On the other hand, the conservative nature of the Saudi society may hinder other behavioral risk factors namely alcohol intake and smoking (especially among women). Finally, the prevalence and clustering of NCDs risk factors are expected to be higher than the general population since the included university's employees were relatively older with more vulnerability to sedentary behavior.

In conclusion, over fifty percent of the studied university's employees had multiple ( $\geq 3$ ) NCDs risk factors. Screening and health promotion initiatives should be launched at least targeting the modifiable NCDs risk factors to avert the excessive risk for cardiovascular disease, diabetes mellitus and several types of cancers.

\section{References}

Al-Hazzaa H (2007). Health enhancing physical activity among Saudi adults using International Physical Activity Questionnaire (IPAQ). Public Health Nutr, 10, 59-64.

Al-Kaabba AF, Al-Hamdan NA, El Tahir A, et al. (2012). 
Tarek Tawfik Amin et al

Prevalence and correlates of dyslipidemia among adults in Saudi Arabia: results from a national survey. Endo Metabo Dis, 2, 89-97.

Al-Nozha M, Al-Hazzaa M, Arafah M, et al (2007). Prevalence of physical activity and inactivity among Saudis aged 30-70 years. Saudi Med J, 28, 559-74.

Al-Nozha MM, Abdullah M, Arafah MR, et al (2007a). Hypertension in Saudi Arabia. Saudi Med J, 28, 77-86.

Alegre MM, Knowles MH, Robison RA, O'Neill KL (2013). Mechanics behind breast cancer prevention-focus on obesity, exercise and dietary fat. Asian Pac J Cancer Prev, 14, 2207-12.

Amin TT, Al Khoudair AS, Al Harbi MA, Al Ali AR (2012). Leisure time physical activity in Saudi Arabia: prevalence, pattern and determining factors. Asian Pac J Cancer Prev, 13, 351-60.

Amin TT, Al-Hammam AM, Almulhim NA, et al (2014). Physical activity and cancer prevention: awareness and meeting the recommendations among adult Saudis. Asian Pac J Cancer Prev, 15, 2597-606.

Amin TT, Suleman W, Ali A, Gamal A, Al Wehedy A (2011). Pattern, prevalence, and perceived personal barriers toward physical activity among adult Saudis in Al-Hassa, KSA. Phys Act Health, 8, 775-66.

Bonett DG, Price RM (2002). Statistical inference for a linear function of medians: confidence intervals, hypothesis testing and sample size requirements. Psychol Methods, 7, 370-383.

Burton WN, Chen C-Y, Conti DJ, Schultz AB, Edington DW (2003). Measuring the relationship between employees' health risk factors and corporate pharmaceutical expenditures. J Occup Environ Med, 45, 793-805.

Cogliano VJ, Baan R, Straif K, et al (2011). Preventable exposures associated with human cancers. J Natl Cancer Inst , 103, 1827-39.

Cust AE (2011). Physical activity and gynecologic cancer prevention. Recent Results Cancer Res, 186, 159-85.

da Costa FF, Benedet J, Leal DJ, de Assis MAA (2013). Clustering of risk factors for non- communicable diseases in adults from Florianopolis, SC. Rev. Bras. Epidemiol, 16, 2.

Ekblom-Bak E, Hellénius M-L, Ekblom O, et al (2010). Independent associations of physical activity and cardiovascular fitness with cardiovascular risk in adults. Eur J Cardiovasc Prev Rehabil, 17, 175-82.

FAO/WHO (2006). Technical consultation on national foodbased dietary guidelines. WHO. regional office. Cairo, Egypt. http://www.fao.org/docrep/010/ai216e/ai216e00. HTM accessed May 2014.

Ferlay J, Shin HR, Bray F, et al (2010). GLOBOCAN 2008, Cancer incidence and mortality worldwide. lyon, France: international agency for research on cancer; 2010. IARC cancer base no. 10. http:// globocan.iarc.fr. Accessed October $20,2013$.

Jafri H, Karas RH (2010). Baseline and on-treatment highdensity lipoprotein cholesterol and the risk of cancer in randomized controlled trials of lipidaltering therapy. $\mathrm{J} \mathrm{Am}$ Coll Cardiol, 55, 2846-55.

Katano S, Nakamura Y, Nakamura A, et al (2010). Relationship among physical activity, smoking, drinking and clustering of the metabolic syndrome diagnostic components. $J$ Atheroscler Thromb, 17, 644-61.

Kearney PM, Whelton M, Whelton PK, He J (2004). Worldwide prevalence of hypertension: a systematic review. Hypertension, 22, 11-21.

Kolbe-Alexander TL,Conradie J,Lambert EV (2013). Clustering of risk factors for non-communicable disease and healthcare expenditure in employees with private health insurance presenting for health risk appraisal: a cross-sectional study.
BMC Public Health, 13, 1213.

Kruk J, Marchlewicz M (2013). Dietary fat and physical activity in relation to breast cancer among Polish women. Asian Pac $J$ Cancer Prev, 14, 2495-502.

Leitzmann MF (2011). Physical activity and genitourinary cancer prevention. Recent Results Cancer Res, 186, 43-71.

Lim SS, Vos T, Flaxman AD, et al (2012). A comparative risk assessment of burden of disease and injury attributable to 67 risk factors and risk factor clusters in 21 regions, 1990-2010: a systematic analysis for the global burden of disease study. Lancet, 380, 2224-57.

McGuire KA, Janssen I, Ross R (2009): Ability of physical activity to predict cardiovascular disease beyond commonly evaluated cardiometabolic risk factors. Am J Cardiol, 104, 1522-33.

Morrison DS, Parr CL, Lam TH, et al (2013). Behavioral and metabolic risk factors for mortality from colon and rectum cancer: analysis of data from the asia-pacific cohort studies collaboration. Asian Pac J Can Prev, 14, 1083-92.

Moura EC, Malta DC, Morais Neto OL, Monteiro CA (2009). Prevalence and social distribution of risk factors for chronic non-communicable diseases in Brazil. Rev Panam Salud Publica, 26, 17-33.

Muniz LC, Schneider BC, Silva IC, Matijasevich A, Santos IS (2012). Accumulated behavioral risk factors for cardiovascular diseases in Southern Brazil. Rev Saude Publica, 46, 534-571.

Murray CJL, Lopez AD (1996) (eds). The global burden of disease: a comprehensive assessment of mortality and disability from disease, injuries, and risk factors in 1990 and projected to 2020. Boston, mass: harvard school of public health.

Musaiger A, Al-Hazzaa H (2012). Prevalence and risk factors associated with nutrition-related noncommunicable diseases in the Eastern Mediterranean region. Int J Gen Med, 199, 217-29.

Musaiger AO, Al Hazzaa MH, Al-Qahtani A, et al (2011). Strategy to combat obesity and to promote physical activity in Arab countries. Diab Metabol Syndr Obes, 4, 89-101.

Musaiger AO, Takruri HR, Hassan AS, Abu-Tarboush H (2012). Food-based dietary guidelines for the Arab Gulf countries. J Nutri Metabol, 2012, 905303.

Ng SW, Zaghloul S, Ali HI, Harrison G, Popkin BM (2011). The prevalence and trends of overweight, obesity and nutritionrelated non-communicable diseases in the Arabian Gulf States. Obesity Reviews, 12, 1-14.

Pickering TG, Hall JE, Appel L, et al (2005). AHA scientific statement: recommendations for blood pressure measurement in humans and experimental animals part 1: blood pressure measurement in humans: a statement for professionals from the subcommittee of professional and public education of the American heart association council on high blood pressure research. Hypertension, 45, 142-59

Plotnikoff RC, McCargar LJ, Wilson PM, Loucaides CA (2005). Efficacy of an E-mail intervention for the promotion of physical activity and nutrition behavior in the workplace context. Am J Health Promot, 19, 422-9.

Poortinga W (2007). The prevalence and clustering of four major lifestyle risk factors in an English adult population. Prev Med, 44, 124-32.

Ramadan EN, Zakaria AM, Elbosaty LM (2013). Prevalence of hypertension and risk factors among university employees of King Khalid in Bisha. J Am Science, 9, 394-404.

Schuit AJ, van Loon AJ, Tijhuis M, Ocke M (2002). Clustering of lifestyle risk factors in a general adult population. Prev Med, 35, 219-24.

Serxner SA, Gold DB, Grossmeier JJ, Anderson DR (2003). The 
relationship between health promotion program participation and medical costs: a dose response. J Occup Environ Med, 45, 1196-201.

Thayyil J, Jayakrishnan TT, Raja M, Cherumanalil JM (2012). Metabolic syndrome and other cardiovascular risk factors among police officers. North Am J Med Sciences, 4, 630-7.

WHO (2002). The world health report 2002: reducing risks, promoting healthy life. Switzerland, Geneva, 162, 57-61.

WHO STEPwise Approach to NCD surveillance, countryspecific STANDARD REPORT, Saudi Arabia report (2005). http://www.who.int/chp/steps/2005_SaudiArabia_STEPS_ Report_EN.pdf.

Wild CP(2012). The role of cancer research in non-communicable disease control. J Natl Cancer Inst jnci.oxfordjournals.org JNCI, Commentary, 1-8.

Wiseman M (2008). The second world cancer research fund/ American Institute for cancer research expert report. Food, nutrition, physical activity, and the prevention of cancer: a global perspective. Proc Nutr Soc, 67, 253-8.

World cancer research fund/american institute for cancer research (AICR) (2007). food, nutrition, physical activity, and the prevention of cancer: a global perspective. Washington, DC. AICR; 2007.

World Health Organization (2011). Global status report on non-communicable diseases 2010-description of the global burden of NCDs, their risk factors and determinants. Geneva, Switzerland: WHO. http://whqlibdoc.who.int/ publications/2011/9789240686458_eng.pdf.

World Health Organization, WHO STEPS instruments and support materials. http://www.who.int/chp/steps/instrument/ en/ accessed February 2012.

World Health Organization. Sedentary lifestyle (2001): a global public health problem, Geneva, Switzerland: WHO 2001. available from: http://www.who.int/hpr/physactiv/sedentary. lifestyle.shtml. 